\title{
Entransy analysis of open thermodynamic systems
}

\author{
CHENG XueTao, WANG WenHua \& LIANG XinGang* \\ Key Laboratory for Thermal Science and Power Engineering of Ministry of Education, Department of Engineering Mechanics, Tsinghua \\ University, Beijing 100084, China
}

Received January 12, 2012; accepted April 17, 2012

\begin{abstract}
The concept of entransy developed in recent years can describe the heat transport ability. This paper extends this concept to the open thermodynamic system and defines the concept of enthalpy entransy. The entransy balance equation of steady open thermodynamic systems, as well as the concept of entransy loss, is developed. The entransy balance equation is applied to analyzing and discussing the air standard cycle. It is found that the entransy loss rate can describe the change in net power output from the cycle but the entropy generation rate cannot when the heat absorbed by the working medium is from the combustion reaction of the gas fuel. When the working medium is heated by a high temperature stream, both the maximum entransy loss rate and the minimum entropy generation rate correspond to the maximum net power output from the cycle. Hence, the concept of entransy loss is an appropriate figure of merit that describes the cycle performance.
\end{abstract}

entransy loss, enthalpy entransy, entransy balance equation, open system, air standard cycle

Citation: $\quad$ Cheng X T, Wang W H, Liang X G. Entransy analysis of open thermodynamic systems. Chin Sci Bull, 2012, 57: 2934-2940, doi: 10.1007/s11434$012-5224-\mathrm{x}$

As nearly $80 \%$ of the total energy consumption is related to heat [1], the optimization design of heat transfer and heatwork conversion has become one of important research topics under the increasing requirements on reducing energy consumption. For instance, the design optimization could improve the performance of heat exchangers and increase heat transfer rate [1]. Optimizing the thermal conductance distribution of the heat exchanger groups could also increase the work output in heat-work conversion [2]. Several theories have been developed for the optimal design of heat transfer and heat-work conversion in recent years [1-7].

Bejan [4-6] developed the constructal theory and thermodynamic optimizations for heat transfer processes. In heat conduction optimization of the Volume-to-Point problem, Bejan [4] developed the constructal theory, in which the basic, imagined structure of the high conductivity material is given, and the aspect ratio of the structure is optimized through theoretical derivation and numerical simulation to decrease the highest temperature of the heated domain. The sub-structure, third degree structure, etc. are evolved to

*Corresponding author (email: liangxg@ tsinghua.edu.cn) cover the whole domain. The constructal theory was found to be effective for heat conduction optimization and was extended to heat convection optimizations [8-10]. Furthermore, Bejan [4-6] related the optimal heat transfer to the minimum production of entropy generation and extended this idea into other systems. Researchers have done many investigations on heat transfer optimization based on the minimum principle of entropy generation $[11,12]$. As the objective of this kind of optimization method is to minimize the entropy generation, it is called thermodynamic optimization.

However, there are arguments on the constructal theory and thermodynamic optimization in heat transfer [6,13-17]. Ghodoossi $[13,14]$ applied the constructal theory to analyzing the effect of the complexity levels of the tree network of conducting paths and found that the heat flow performance does not essentially improve if the internal complexity of the heat generating area increases. In heat convection, Escher et al. [16] showed that the parallel channel network achieves a more than fivefold higher performance coefficient than the bifurcating tree-like network with a constant flow rate, while almost four times more heat can be removed for a constant pressure gradient across the networks. For the minimum 
principle of entropy generation, it was noted that the heat exchanger effectiveness does not always increase with decreasing entropy generation when the concept of entropy generation is used to analyze heat exchangers [6]. Instead, it may become smaller under some conditions. Shah and Skiepko [17] also observed that the heat exchanger effectiveness can be maximum, intermediate or minimum at the maximum entropy generation in their discussion of 18 kinds of heat exchangers. Therefore, the minimum entropy generation principle is not always appropriate to heat transfer optimization.

In the last decade, Guo et al. [7] introduced a new physical parameter, entransy, which describes the heat transport ability. The new concept was proposed by the analogy between heat and electrical conductions [7]. Heat flow corresponds to electrical current, thermal resistance to electrical resistance, temperature to electric voltage, and heat capacity to capacitance. Entransy is actually the potential energy of the heat in a body, corresponding to the electrical energy in a capacitor. For an object whose internal energy is $U$ and temperature is $T$, its entransy is defined as [7]

$$
G=\frac{1}{2} U T .
$$

When heat is transferred from a high temperature object to a low temperature one, it was proved that entransy dissipation will always be produced $[7,18]$. So, the concept of entransy could describe the irreversibility of heat transfer [7,18-20]. Furthermore, Cheng et al. [18,21,22] set up the thermal equilibrium criteria based on the concept of entransy, developed a microscopic expression of entransy for a monatomic ideal gas system, related the entransy to the microstate number, indicated the microscopic physical meaning of entransy to some extent, and extended the entransy theory to generalized flows. Xu [23] discussed entransy and entransy dissipation from the thermodynamic viewpoint. Based on the concept of entransy and entransy dissipation, Guo et al. [7] derived the minimum entransy dissipation principle for prescribed heat flux boundary conditions and the maximum entransy dissipation principle for prescribed temperature boundary conditions. These principles are named as the extremum entransy dissipation principle. They further defined the entransy-dissipation-based thermal resistance. Then, the extremum entransy dissipation principle is evolved into the minimum thermal resistance principle that is much easier for understanding.

The principles based on the concept of entransy were also used to optimize the Volume-to-Point problem [7]. For this problem, a Lagrange function was formed based on the extremum entransy dissipation principle with the limitation of finite high conductivity material. By pursing the extremum value of this Lagrange function, a rule of uniform distribution of temperature gradient was obtained mathematically. By putting the high conductivity materials at the place where the temperature gradient is highest, the construct of high conductivity materials was formed step by step and the average temperature of the volume was reduced effectively. It has been shown that the average temperature of the heated domain thus obtained is lower than that by the constructal theory [7,24]. Chen et al. [25] compared the entransy theory with the minimum principle of entropy generation, and showed that the entransy theory could lead to a lower average temperature of the volume than the minimum principle of entropy generation. Other researches also indicate that the entransy theory is suitable for the optimizations of heat conduction [26,27], heat convection [28], thermal radiation $[29,30]$ and heat exchangers [1,31-34]. In addition, there is no paradox similar to the entropy generation when the entransy theory is used to analyze heat exchanger [1,32].

For heat-work conversion, the concept of entropy has been widely used [2,3,35-39]. Entropy was first defined based on the reversible cycle of the Carnot engine in 1854 [40]. In any irreversible process, entropy generation exists. During a physical process, the more entropy generation is, the more the system loses the ability of doing work [40]. With this consideration, entropy generation has been used to optimize thermodynamic processes so as to decrease the ability loss of doing work and to increase the work output [2]. For instance, Chen et al. [2] revealed that the minimum entropy generation always corresponds to the maximum work output in the optimization of thermodynamic process with heat exchanger groups. When analyzing an absorption chiller, Myat et al. [39] showed that the minimization of entropy generation in absorption cycle leads to the maximization of the COP.

On the other hand, the applicability of the entransy theory on the optimization of the thermodynamic processes with work was also discussed from different viewpoints [2,41]. Chen et al. [2] thought that the concept of entransy dissipation could not be used to optimize heat-work conversion in closed thermodynamic systems. Wu [41] defined the conversion entransy and used the definition to optimize closed thermodynamic cycles.

From above discussion, it could be found that the entransy theory is effective in heat transfer optimization, while the concept of entropy is not always. In heat-work conversion, the concept of entropy is widely used. However, there are still no definite conclusions for the applicability of the entransy theory because researchers have different opinions $[2,41]$. The existing reports on the applicability of the entransy theory to heat-work conversion are all about closed systems. It is worth of making an investigation on the open thermodynamic systems. This paper explores the applicability of entransy theory to the open systems with heat-work conversion.

\section{Enthalpy entransy}

For any thermodynamic process, the first law of thermody- 
namics gives

$$
\delta Q=\mathrm{d} U+\delta W
$$

where $\delta Q$ is the absorbed heat, $\mathrm{d} U$ is the change of the internal energy and $\delta W$ is the output work. Multiplying eq. (2) by the working medium temperature, $T$, leads to

$$
T \delta Q=T \mathrm{~d} U+T \delta W,
$$

where the left term is the heat entransy flow as it is associated with heat $\delta Q$, and the second term on the right hand is called work entransy flow as it is associated with work $\delta W$. Considering an ideal gas system with constant specific heat capacity at constant volume, $c_{V}$, the first term on the right hand could be expressed as

$$
T \mathrm{~d} U=T \mathrm{~d}\left(c_{V} m T\right)=\mathrm{d}\left(\frac{1}{2} c_{V} m T^{2}\right)=\mathrm{d}\left(\frac{1}{2} U T\right)=\mathrm{d} G,
$$

where $m$ is the mass. The first term on the right hand of eq. (3) indicates the change of entransy.

The entransy associated with work, heat flow and internal energy are all defined in eq. (3). However, there is no definition for entransy change related to enthalpy though it is a very important parameter in thermodynamics. We will define the enthalpy entransy below.

For a thermodynamic system, the definition of enthalpy is

$$
H=U+p V,
$$

where $p$ is the pressure and $V$ is the volume of the system. Based on eq. (5), the differentiation of the enthalpy is

$$
\mathrm{d} H=\mathrm{d}(U+p V)=\mathrm{d} U+\mathrm{d}(p V) .
$$

Multiplying eq. (6) by temperature results in

$$
T \mathrm{~d} H=T \mathrm{~d} U+T \mathrm{~d}(p V),
$$

where the left part of eq. (7) could be defined as the change of enthalpy entransy as it is associated with enthalpy $\mathrm{d} H$. For an ideal gas system, we have

$$
\begin{aligned}
T \mathrm{~d} H & =T \mathrm{~d}\left(c_{V} m T\right)+T \mathrm{~d}(m R T) \\
& =\mathrm{d}\left[\frac{1}{2}\left(c_{V}+R\right) m T^{2}\right] \\
& =\mathrm{d}\left(\frac{1}{2} c_{p} m T^{2}\right)=\mathrm{d}\left(\frac{1}{2} H T\right),
\end{aligned}
$$

where $m$ is the gas mass, $R$ is the gas constant, and $c_{p}$ is the specific heat capacity at constant pressure. The integration of eq. (8) yields

$$
\int_{0}^{H} T \mathrm{~d} H=\int_{0}^{T} \mathrm{~d}\left(\frac{1}{2} H T\right)=\frac{1}{2} H T .
$$

Based on eq. (5), the enthalpy entransy of the ideal gas system could be defined as

$$
G_{H}=\frac{1}{2} H T
$$

The entransy balance equation of open ideal gas systems is set up in the following section based on eqs. (8) and (10).

\section{Entransy balance equation of open systems}

A steady open system is shown in Figure 1. According to the first law of thermodynamics, there is [42]

$$
\delta Q=\mathrm{d} U+\delta W_{\mathrm{f}}+\delta W_{\text {net }},
$$

where $\delta Q$ is the absorbed heat, $\mathrm{d} U$ is the change in the internal energy of the working medium, $\delta W_{\text {net }}$ is the net output work, and $\delta W_{\mathrm{f}}$ is the change in the flow work whose expression is

$$
\delta W_{\mathrm{f}}=\mathrm{d}(p V) .
$$

Eq. (11) can be expressed as [42]

$$
\delta Q=\mathrm{d} U+\mathrm{d}(p V)+\delta W_{\text {net }}=\mathrm{d} H+\delta W_{\text {net }} .
$$

Multiplying eq. (13) by temperature, we have

$$
T \delta Q=T \mathrm{~d} H+T \delta W_{\text {net }} .
$$

Substituting eqs. (8) and (10) into eq. (14) yields

$$
\delta G_{Q}=\mathrm{d} G_{H}+\delta G_{W \text {-net }},
$$

where

$$
\begin{gathered}
\delta G_{Q}=T \delta Q, \\
\delta G_{W \text {-net }}=T \delta W_{\text {net }},
\end{gathered}
$$

$\delta G_{Q}$ is the entransy flow due to heat exchange, $\mathrm{d} G_{H}$ is the change in the enthalpy entransy, and $\delta G_{W \text {-net }}$ is the net work entransy flow of the working medium. It could be found that part of the absorbed heat entransy flow goes into the working medium, making the enthalpy entransy increase, while the rest is used to do work. Eq. (15) is the entransy balance for steady open systems.

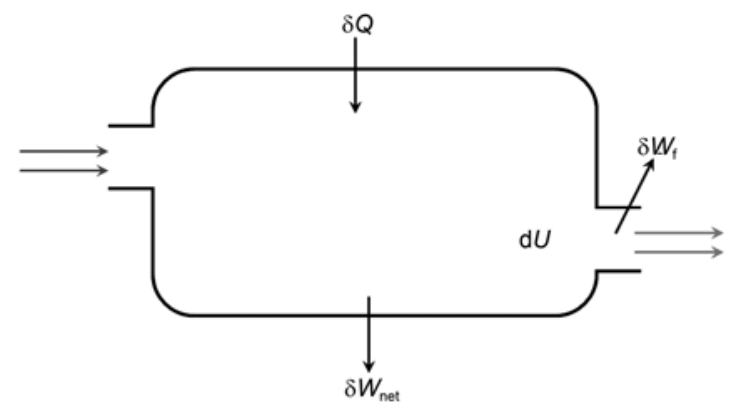

Figure 1 Sketch of an open thermodynamic system. 


\section{Analyses of the air standard cycle}

The air standard cycle is widely used in engineering. As shown in Figure 2, the working medium is compressed through an isentropic process, increasing its temperature from $T_{1}$ to $T_{2}$. Then, it absorbs heat during an isobaric process, and its temperature gets to $T_{3}$. After that, it does work during the second isentropic process and its temperature decreases to $T_{4}$. Finally, the used working medium is discharged into the environment, making its temperature back to the initial value after a cycle. The working medium in the cycle is the gas mixture after the combustion reaction of the gas fuel. The working medium can still be treated as the air because about $80 \%$ of the air is nitrogen which does not take part in the combustion reaction. Then, the heat generated from the combustion reaction could be treated as that absorbed from an inner heat source.

Assume that the air could be treated as the ideal gas. As the working medium gets back to the initial state after a cycle, its enthalpy will not change. From energy conservation, the output power is

$$
\dot{W}_{\mathrm{net}}=\dot{Q}-\dot{Q}_{0}=\dot{Q}\left(1-\frac{\dot{Q}_{0}}{\dot{Q}}\right)=\dot{Q}\left(1-\frac{T_{4}-T_{1}}{T_{3}-T_{2}}\right),
$$

where $\dot{Q}$ is the heat generation rate from the combustion reaction, and $\dot{Q}_{0}$ is the heat rate released to the environment by the used working medium. In the air standard cycle, there is [42]

$$
\frac{T_{1}}{T_{2}}=\frac{T_{4}}{T_{3}}=\frac{T_{4}-T_{1}}{T_{3}-T_{2}} .
$$

Therefore

$$
\dot{W}_{\text {net }}=\dot{Q}\left(1-T_{1} / T_{2}\right) \text {. }
$$

On the other hand, the cycle in Figure 2 can be analyzed from the entransy point of view. The cycle system is composed of the working medium and the environment. The enthalpy entransy of the working medium will not change when a cycle is finished. According to eq. (15), the net work

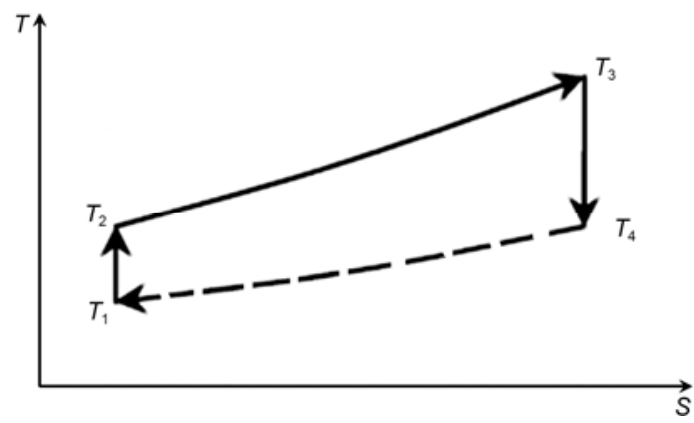

Figure 2 Sketch of the air standard cycle. entransy flow rate of the cycle is

$$
\dot{G}_{W-\text { net }}=\dot{G}_{Q}-\dot{G}_{Q 0},
$$

where $\dot{G}_{Q}$ is the absorbed heat entransy flow rate, and $\dot{G}_{Q 0}$ is that gets out of the working medium.

When the used working medium is discharged into the environment, it is cooled and its temperature decreases to the initial value. This process is a heat transfer process during which entransy dissipation is produced $[7,18]$. The entransy dissipation rate is

$$
\dot{G}_{\mathrm{dis}}=\dot{G}_{Q 0}-\dot{G}_{Q-\mathrm{e}},
$$

where $\dot{G}_{Q-\mathrm{e}}$ is the heat entransy flow that gets into the environment.

For the whole system, it could be found that some of $\dot{G}_{Q}$ is used to do work, some is dissipated during the cooling process of the used working medium, and the rest is released into the environment. Therefore, the entransy loss rate of the system is defined as

$\dot{G}_{\text {loss }}=\dot{G}_{W \text {-net }}+\dot{G}_{\text {dis }}=\dot{G}_{Q}-\dot{G}_{Q 0}+\dot{G}_{Q 0}-\dot{G}_{Q-\mathrm{e}}=\dot{G}_{Q}-\dot{G}_{Q-\mathrm{e}}$.

Considering the processes in Figure 2,

$$
\dot{G}_{Q}=\frac{1}{2} H_{3} T_{3}-\frac{1}{2} H_{2} T_{2}=\frac{1}{2} c_{p} \dot{m}\left(T_{3}^{2}-T_{2}^{2}\right),
$$

where $\dot{m}$ is the working medium circulation rate. As there is no work during the heat transfer process between the used working medium and the environment, according to eq. (15),

$$
\dot{G}_{Q-\mathrm{e}}=\dot{G}_{H-\mathrm{e}}=\dot{Q}_{0} T_{1}
$$

where $\dot{G}_{H-\mathrm{e}}$ is the increase rate in the environment enthalpy entransy. Therefore, from eq. (19), we have

$$
\begin{aligned}
\dot{G}_{\mathrm{loss}} & =\frac{1}{2} c_{p} \dot{m}\left(T_{3}^{2}-T_{2}^{2}\right)-\dot{Q}_{0} T_{1} \\
& =\frac{1}{2} c_{p} \dot{m}\left[\left(T_{2}+\frac{\dot{Q}}{c_{p} \dot{m}}\right)^{2}-T_{2}^{2}\right] \\
& =\frac{\dot{Q}^{2}}{2 c_{p} \dot{m}}+\dot{Q} T_{2}\left(1-\frac{T_{1}^{2}}{T_{2}^{2}}\right)
\end{aligned}
$$

Eq. (20) indicates that the net power output increases with increasing $\dot{Q}$ and $T_{2}$ or with decreasing of $T_{1}$. At the same time, the entransy loss rate also increases with increasing $\dot{Q}$ and $T_{2}$ or with decreasing $T_{1}$. Therefore, the entransy loss rate could describe the change of the net power for the air standard cycle.

Let us analyze the entropy change rate in the air standard 
cycle. The entropy generation rate induced by dumping the used working medium into the environment should be considered as indicated by [43]. The entropy generation rate can be calculated by

$$
\dot{S}_{\mathrm{g}}=c_{p} \dot{m} \ln \frac{T_{3}}{T_{2}}+c_{p} \dot{m} \ln \frac{T_{1}}{T_{4}}+\frac{\dot{Q}_{0}}{T_{1}},
$$

where the first term on the right hand is the entropy increase rate when the working medium absorbs heat, the second term is the entropy decrease rate when the working medium releases heat into the environment, and the last term is the entropy increase rate of the environment. From eqs. (18) and (19), eq. (27) reduces to

$$
\dot{S}_{\mathrm{g}}=c_{p} \dot{m} \ln \frac{T_{1} T_{3}}{T_{2} T_{4}}+\frac{\dot{Q}_{0}}{T_{1}}=\frac{\dot{Q}}{T_{2}} .
$$

Eq. (28) tells that the entropy generation rate declines with increasing $T_{2}$. However, the entropy generation rate will increase with increasing $\dot{Q}$. When $\dot{Q}$ and $T_{2}$ are prescribed, the entropy generation rate will not change with $T_{1}$. Considering the variation tendency of the net power, one could find that the entropy generation rate cannot describe the change of the net power in the air standard cycle.

As shown in Figure 3, we consider another case in which the heat absorbed by the working medium is not from the combustion reaction but from a high temperature stream through a counter flow heat exchanger. The heat capacity flow rate, the inlet and the outlet temperatures of the high temperature stream are $C_{\mathrm{H}}, T_{\mathrm{H} \text {-in }}$ and $T_{\mathrm{H} \text {-out }}$, respectively. The heat rate from the high temperature stream is [44]

$$
\begin{aligned}
\dot{Q} & =C_{\mathrm{H}-\min }\left(T_{\mathrm{H}-\mathrm{in}}-T_{2}\right) \varepsilon_{\mathrm{H}} \\
& =C_{\mathrm{H}-\min }\left(T_{\mathrm{H}-\mathrm{in}}-T_{2}\right) \frac{1-\exp \left[-\mathrm{NTU}\left(1-C^{\mathrm{H}^{*}}\right)\right]}{1-C^{\mathrm{H}^{*}} \exp \left[-\mathrm{NTU}\left(1-C^{\mathrm{H}^{*}}\right)\right]},
\end{aligned}
$$

where NTU is the number of the heat transfer unit of the heat exchanger, $C_{\mathrm{H}-\mathrm{min}}$ is the smaller one between $C_{\mathrm{H}}$ and

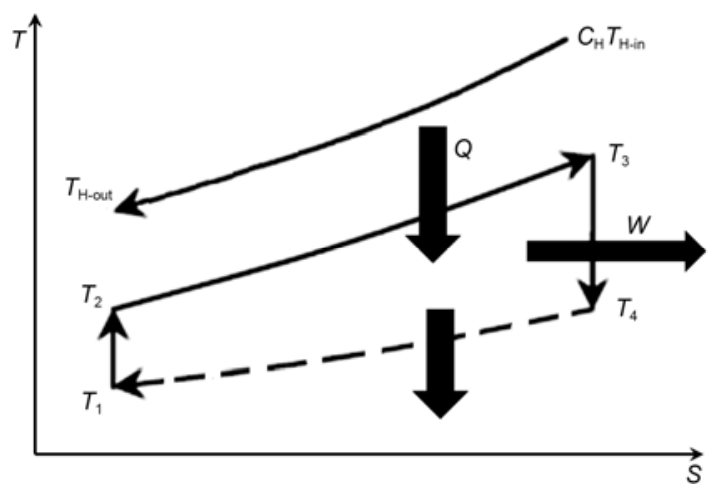

Figure 3 Sketch of the air standard cycle when the working medium is heated by a high temperature stream. $c_{p} \dot{m}, \varepsilon_{\mathrm{H}}$ is the effectiveness, and

$$
C^{\mathrm{H}^{*}}=\min \left(C_{\mathrm{H}}, c_{p} \dot{m}\right) / \max \left(C_{\mathrm{H}}, c_{p} \dot{m}\right) .
$$

Based on eq. (29), the net power can be calculated by eq. (20).

Let us analyze the cycle from the entransy viewpoint. As the used high temperature stream and the used working medium are to be discharged into the environment, the entransy dissipation rate produced in the discharging process should be considered. According to eq. (15), some of the heat entransy flow rate from the high temperature stream is dissipated during the heat transfer process between the stream and the working medium and in the discharging processes of the used high temperature stream and the used working medium, some is used for doing work, and the rest is released into the environment. Therefore,

$$
\dot{G}_{\mathrm{f}-\mathrm{h}}=\dot{G}_{\mathrm{dis}}+\dot{G}_{W \text {-net }}+\dot{G}_{Q \text {-e }},
$$

where $\dot{G}_{\text {f-h }}$ is the heat entransy flow rate from the high temperature stream, which is expressed as

$$
\dot{G}_{\mathrm{f}-\mathrm{h}}=\frac{1}{2} C_{\mathrm{H}}\left(T_{\mathrm{H}-\mathrm{in}}^{2}-T_{1}^{2}\right) \text {. }
$$

$\dot{G}_{Q-\mathrm{e}}$ is calculated by

$\dot{G}_{Q-\mathrm{e}}=\dot{Q}_{\mathrm{e}} T_{1}=\left(\dot{Q}_{\mathrm{all}}-\dot{W}_{\mathrm{net}}\right) T_{1}=\left[C_{\mathrm{H}}\left(T_{\mathrm{H}-\mathrm{in}}-T_{1}\right)-\dot{W}_{\text {net }}\right] T_{1}$,

where $\dot{Q}_{\mathrm{e}}$ is the total heat rate released to the environment, including the heat released by the used high temperature stream; and $\dot{Q}_{\text {all }}$ is the total heat from the high temperature stream. It could be found that some entransy flow rate is lost in heat transfer, while some other is lost when the working medium does work. Therefore,

$$
\begin{aligned}
\dot{G}_{\text {loss }} & =\dot{G}_{\text {dis }}+\dot{G}_{W \text {-net }} \\
& =\dot{G}_{\text {f-h }}-\dot{G}_{Q-\mathrm{e}} \\
& =\frac{1}{2} C_{\mathrm{H}}\left(T_{\mathrm{H}-\mathrm{in}}^{2}-T_{1}^{2}\right)-\left[C_{\mathrm{H}}\left(T_{\mathrm{H}-\mathrm{in}}-T_{1}\right)-\dot{W}_{\text {net }}\right] T_{1} \\
& =\frac{1}{2} C_{\mathrm{H}}\left(T_{\mathrm{H}-\mathrm{in}}-T_{1}\right)^{2}+\dot{W}_{\text {net }} T_{1} .
\end{aligned}
$$

The entransy loss rate increases monotonously with increasing net power when $C_{\mathrm{H}}, T_{\mathrm{H}}$ and $T_{1}$ are prescribed. The maximum entransy loss rate corresponds to the maximum net power output from the cycle.

If the concept of entropy is used to analyze the cycle, there is

$$
\begin{aligned}
\dot{S}_{\mathrm{g}} & =C_{\mathrm{H}} \ln \frac{T_{1}}{T_{\mathrm{H}-\mathrm{in}}}+\frac{\dot{Q}_{\mathrm{all}}-\dot{W}_{\mathrm{net}}}{T_{1}} \\
& =C_{\mathrm{H}} \ln \frac{T_{1}}{T_{\mathrm{H}-\mathrm{in}}}+\frac{C_{\mathrm{H}}\left(T_{\mathrm{H}-\mathrm{in}}-T_{1}\right)-\dot{W}_{\mathrm{net}}}{T_{1}},
\end{aligned}
$$


where the first term on right hand expresses the entropy decrease rate of the high temperature stream, and the second term is the entropy increase rate of the environment. It could be found that the entropy generation rate reduces monotonously with increasing net power output. Therefore, the minimum entropy generation rate corresponds to the maximum net power of the cycle.

A numerical example is shown below. Assume that $C_{\mathrm{H}}=2$ $\mathrm{W} / \mathrm{K}, c_{p}=1000 \mathrm{~J} /(\mathrm{kg} \mathrm{K}), \dot{m}=0.001 \mathrm{~kg} / \mathrm{s}, \mathrm{NTU}=2, T_{\text {in }}=$ $420 \mathrm{~K}$ and $T_{1}=300 \mathrm{~K}$. In this case, temperature $T_{2}$ should be optimized to increase the net power output from the cycle as much as possible. The variations of the net power output, the entransy loss rate and the entropy generation rate with $T_{2}$ are calculated by eqs. (20), (34) and (35). The results are shown in Figure 4. The net power output and the entransy loss rate both reach to the maximum value when $T_{2}$ is 355.2 $\mathrm{K}$, while the entropy generation rate reaches the minimum value at the same time. The numerical results are in agreement with the above analyses.

\section{Conclusion}

In this paper, the concept of enthalpy entransy is defined. Based on the definition, the entransy balance equation for steady, open thermodynamic system is developed. It is found that part of the absorbed heat entransy flow runs into the working medium and makes its enthalpy entransy increase, while the rest is used to do work. The entransy of the steady, open thermodynamic processes is in balance.

The air standard cycle is analyzed and discussed based on the entransy balance equation. When the heat absorbed by the working medium is from the combustion reaction of the gas fuel, the entransy loss rate could describe the change in the net power output from the cycle, but the entropy generation rate cannot. When the heat absorbed by the working medium is from a high temperature stream, both the maximum

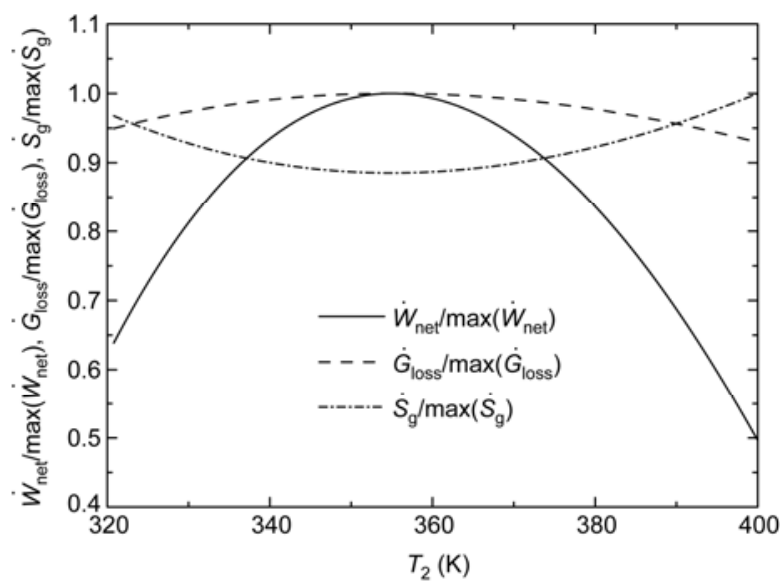

Figure 4 Variations of the net power output, the entransy loss rate and the entropy generation rate with $T_{2}$. entransy loss rate and the minimum entropy generation rate correspond to the maximum net power output from the cycle. On the whole, the entransy loss can describe the cycle performance.

This work was supported by the National Natural Science Foundation of China (51106082) and the Tsinghua University Initiative Scientific Research Program.

1 Qian X D, Li Z X. Analysis of entransy dissipation in heat exchangers. Int J Therm Sci, 2011, 50: 608-614

2 Chen $\mathrm{Q}$, Wu J, Wang M R, et al. A comparison of optimization theories for energy conservation in heat exchanger groups. Chin Sci Bull, 2011, 56: 449-454

3 Moran M J. Availability Analysis: A Guide to Efficient Energy Use. New Jersey: Prentice-Hall Inc, 1982

4 Bejan A. Constructal-theory network of conducting paths for cooling a heat generating volume. Int J Heat Mass Transfer, 1997, 40: 779816

5 Bejan A. A study of entropy generation in fundamental convective heat transfer. ASME J Heat Transfer, 1979, 101: 718-725

6 Bejan A. Second-law analysis in heat transfer and thermal design. Adv Heat Transfer, 1982, 15: 1-58

7 Guo Z Y, Zhu H Y, Liang X G. Entransy-A physical quantity describing heat transfer ability. Int J Heat Mass Transfer, 2007, 50: 2545-2556

8 Wu W J, Chen L G, Sun F R. Heat-conduction optimization based on constructal theory. Appl Energ, 2007, 84: 39-47

9 Tondeur D, Luo L G. Design and scaling laws of ramified fluid distributors by the constructal approach. Chem Eng Sci, 2004, 59: 17991813

10 Pence D V. Reduced pumping power and wall temperature in microchannel heat sinks with fractal-like branching channel networks. Microsc Therm Eng, 2002, 6: 319-331

11 Poulikakos D, Bejan A. Fin geometry for minimum entropy generation in forced convection. ASME J Heat Transfer, 1982, 104: 616623

12 Erek A, Dincer I. An approach to entropy analysis of a latent heat storage module. Int J Therm Sci, 2008, 47: 1077-1085

13 Ghodoossi L. Entropy generation rate in uniform heat generating area cooled by conducting paths: Criterion for rating the performance of constructal designs. Energ Convers Manage, 2004, 45: 2951-2969

14 Ghodoossi L. Conceptual study on constructal theory. Energ Convers Manage, 2004, 45: 1379-1395

15 Ghodoossi L. Thermal and hydrodynamic analysis of a fractal microchannel network. Energ Convers Manage, 2005, 46: 771-788

16 Escher W, Michel B, Poulikakos D. Efficiency of optimized bifurcating tree-like and parallel microchannel networks in the cooling of electronics. Int J Heat Mass Transfer, 2009, 52: 1421-1430

17 Shah R K, Skiepko T. Entropy generation extrema and their relationship with heat exchanger effectiveness-Number of transfer unit behavior for complex flow arrangements. J Heat Transfer, 2004, 126: 994-1002

18 Cheng X T, Liang X G, Guo Z Y. Entransy decrease principle of heat transfer in an isolated system. Chin Sci Bull, 2011, 56: 847-854

19 Cheng X T, Liang X G, Xu X H. Microscopic expression of entransy. Acta Phys Sin, 2011, 60: 060512

20 Liu W, Liu Z C, Jia H, et al. Entransy expression of the second law of thermodynamics and its application to optimization in heat transfer process. Int J Heat Mass Transfer, 2011, 54: 3049-3059

21 Cheng X T, Xu X H, Liang X G. Principles of potential entransy in generalized flow. Acta Phys Sin, 2011, 60: 118103

22 Cheng X T, Dong Y, Liang X G. Potential entransy and potential entransy decrease principle. Acta Phys Sin, 2011, 60: 114402

$23 \mathrm{Xu} \mathrm{M} \mathrm{T.} \mathrm{The} \mathrm{thermodynamic} \mathrm{basis} \mathrm{of} \mathrm{entransy} \mathrm{and} \mathrm{entransy} \mathrm{dissipa-}$ 
tion. Energy, 2011, 36: 4272-4277

24 Chen L G, Wei S H, Sun F R. Constructal entransy dissipation minimization for 'volume-point' heat conduction. J Phys D: Appl Phys, 2008, 41: 195506

25 Chen Q, Zhu H Y, Pan N, et al. An alternative criterion in heat transfer optimization. P Roy Soc A Math Phy, 2011, 467: 1012-1028

26 Xiao Q H, Chen L G, Sun F R. Constructal entransy dissipation rate minimization for "disc-to-point" heat conduction. Chin Sci Bull, 2011, 56: $102-112$

27 Cheng X T, Xu X H, Liang X G. Homogenization of temperature field and temperature gradient field. Sci China Ser E-Tech Sci, 2009, 52: 2937-2942

28 Chen Q, Wang M, Pan N, et al. Optimization principles for convective heat transfer. Energy, 2009, 34: 1199-1206

29 Cheng X T, Liang X G. Entransy flux of thermal radiation and its application to enclosures with opaque surfaces. Int J Heat Mass Transfer, 2011, 54: 269-278

30 Cheng X T, Xu X H, Liang X G. Radiative entransy flux in enclosures with non-isothermal or non-grey, opaque, diffuse surfaces and its application. Sci China Tech Sci, 2011, 54: 2446-2456

31 Xia S J, Chen L G, Sun F R. Optimization for entransy dissipation minimization in heat exchanger. Chin Sci Bull, 2009, 54: 3572-3578

32 Guo Z Y, Liu X B, Tao W Q, et al. Effectiveness-thermal resistance method for heat exchanger design and analysis. Int $\mathrm{J}$ Heat Mass Transfer, 2010, 53: 2877-2884

33 Guo J F, Xu M T, Chen L. The entransy dissipation minimization principle under given heat duty and heat transfer area conditions. Chin Sci Bull, 2011, 56: 2071-2076
34 Li X F, Guo J F, Xu M T, et al. Entransy dissipation minimization for optimization of heat exchanger design. Chin Sci Bull, 2011, 56: 2174-2178

35 Ust Y, Sahin B, Safa A. The effects of cycle temperature and cycle pressure ratios on the performance of an irreversible otto cycle. Acta Phys Polonica A, 2011, 120: 412-416

36 Mistry K H, Lienhard J H, Zubair S M. Effect of entropy generation on the performance of humidification-dehumidification desalination cycles. Int J Thermal Sci, 2010, 49: 1837-1847

37 Maheshwar G, Chaudhary S, Somani S K. Performance analysis of endoreversible combined Carnot cycles based on new maximum efficient power (MEP) approach. Int J Low Carbon Tech, 2010, 5: 1-6

38 Adavbiele A S. Optimization of thermofluid systems with second law. Int J Eng Research Africa, 2010, 1: 67-80

39 Myat A, Thu K, Kim Y D. A second law analysis and entropy generation minimization of an absorption chiller. Appl Therm Eng, 2011, 31: 2405-2413

40 Zhao K H, Luo W Y. Thermotics (in Chinese). Beijing: Higher Education Press, 2002

41 Wu J. Potential energy (Entransy) in thermal science and its application (in Chinese). Dissertation for Doctoral Degree. Beijing: Tsinghua University, 2009. 72-106

42 Chen Z S. Advance engineering thermodynamics (in Chinese). Beijing: Higher Education Press, 2008

43 Bejan A. Entropy Generation Minimization. Florida: CRC Press, 1996

44 Yang S M, Tao W Q. Heat Transfer (in Chinese). Beijing: Higher Education Press, 1998

Open Access This article is distributed under the terms of the Creative Commons Attribution License which permits any use, distribution, and reproduction in any medium, provided the original author(s) and source are credited. 